\title{
STOCHASTIC QUALITY-COST OPTIMIZATION SYSTEM HYBRIDIZING MULTI-OBJECTIVE GENETIC ALGORITHM AND QUALITY FUNCTION DEPLOYMENT
}

\author{
Tae-Kyung LIM"a, Won-Suk JANG ${ }^{\text {, }}$, Jae-ho CHOI ${ }^{\mathrm{c}}$, Dong-Eun LEE ${ }^{\mathrm{d}}$ \\ ${ }^{a}$ School of Architecture and Civil Engineering, Kyungpook National University, \\ 1370 Sangyegk-Dong, Buk-Gu, DaeGu, 702-701, Korea \\ ${ }^{b}$ Department of Civil Engineering, Yeungman University, 214-1 Dae-Dong, \\ Gyeongsa-Si, Gyeongsangbuk-Do, 712-749, Korea \\ ${ }^{c}$ Department of Civil Engineering, Dong-A University, P4401, 840 Hadan2-dong, \\ Saha-gu, Busan, 604-714, Korea \\ ${ }^{d}$ School of Architecture and Civil Engineering, Kyungpook National University, \\ 1370 Sangyegk-dong, Buk-gu, Daegu, 702-701, Korea
}

Received 09 Jun 2012; accepted 19 Nov 2012

\begin{abstract}
This paper introduces an automated tool, the stochastic quality-cost optimization (SQCO) system, that hybridizes multi-objective genetic algorithm (MOGA) and Quality Function Deployment (QFD). The system identifies the optimal trade-off between a construction owner's satisfaction and a contractor's satisfaction. It is important to reconcile the project participants' conflicting interests because the construction owner aims to maximize the quality of construction while the contractor aims to minimize the cost of construction. MOGA is used to optimize resource allocation when owner satisfaction and contractor satisfaction are pursued at the same time under a limited budget. Multi-objective optimization is integrated with simulation to effectively deal with the uncertainties of the QFD input and the variability of the QFD output. This study is of value to practitioners because SQCO allows for the establishment of a quality plan that satisfies all of the multi project participants. The study is also of relevance to researchers in that it allows researchers to expeditiously identify an optimal design alternative of construction methods and operations. A test case implemented with a curtain-wall unit verifies the usability and validity of the system in practice.
\end{abstract}

Keywords: building envelope, curtain-wall, Quality Function Deployment (QFD), cost, quality, optimization, multiobjective genetic algorithm.

\section{Introduction}

A curtain-wall is an exterior cladding system that constitutes a building envelope and affects the building's aesthetic appearance. Particularly, curtain-wall operation is critical in tall building construction because it accounts for 10 to $15 \%$ of the total project cost (Eisele, Kloft 2002; Chew et al. 2004; Efstathiades et al. 2007). Designing a new system involves in always a tradeoff between quality goals and limited budgets (Tsai, Chang 2004; Fayek et al. 2010). Since curtain-wall design is also a techno-economic process, curtain-wall unit cost is a critical factor in determining if the design alternative is acceptable or not. For sure, optimizing the quality and cost of curtain-wall design provides an opportunity to reduce project cost. However, selecting the optimum design alternative is a multi-participant decision-making task involving multiple attributes (i.e. several performance variables) that need to be considered.
A design-bid-build (DBB) project proceeds in two distinct steps, i.e. selecting a designer to prepare complete and detailed plans and specifications for the project, and soliciting bids for construction by using the plans and specifications. Therefore, the contractor would have no opportunity in the process for developing the design when DBB is used; a design-build (DB) project entails the award of a single contract to one entity called a design-build contractor that is responsible for both design and construction. It provides collaborative teaming process, encourages design innovation by providing more opportunities to evaluate design alternatives. Therefore, an optimum design alternative can be identified earlier and refined throughout, yielding most appropriate design to meet the owner's goals. A project will benefit from value engineering (VE) and design innovation resulting in substantial cost savings when DB is used. It is well accepted that design-build (DB) is advantageous than

Corresponding author: Dong-Eun Lee

E-mail: dolee@knu.ac.kr 
design-bid-build (DBB) in securing to deliver a project within the budget and the estimated construction period and to get satisfied with the quality of the project (Ojo et al. 2011).

Generally, the project participants (i.e. the construction owner and the contractor) of a design-build project have conflicting interests relative to the quality and the cost of a design alternative. The construction owner (or the owner's representative) aims to maximize the quality of the constructed facility by urging the contractor to invest as much as possible in the actual production; the contractor aims to maximize the satisfaction of the higher management by minimizing the production cost, that is, by maximizing company profit. The more the contractor invests, it is likely that the owner's satisfaction with quality will increase and the contractor's satisfaction with profits will decrease. The conflicting interests between the construction owner and the contractor are mostly caused by a budget specified in the contract.

Depending on the planned costs that are allocated to the components of a construction product, design alternatives vary. In other words, a set of planned costs assigned to the components results in a unique design alternative. The optimum design alternative has planned costs that maximize the satisfaction of both the construction owner and the contractor. An automated system that identifies the planned costs of curtain-wall components resulting in the optimum trade-off between the quality and the cost of a design alternative would facilitate multi-attribute and multi-participant decision making. The system identifies the trade-off between the conflicting interests pursued by the project participants by considering the constraints specified in a contract.

The existing QFD computes the priorities of technical attributes (TAs), and quantifies the customer satisfaction by identifying customer requirements (CRs) and their importance weights, technical attributes (TAs) and their importance weights, and the degrees of relationship between CRs and TAs. Quality function deployment is accepted as an effective method and to identify the factors to improve the quality of product and/or service in building construction (Tchidi et al. 2012). However, the cost dimension is not incorporated into the QFD process (King 1987). Integrating the cost dimension into QFD may provide an opportunity to maximize customer satisfaction subject to cost and other organizational constraints (Wasserman 1993). In addition, Bode and Fung (1998) insist that existing QFD applications are technically onesided, because they assume infinite resource availability and ignore the fact that an enterprise is usually an economic entity that tries to balance the trade-off between quality and cost. As such, QFD researchers have so far devoted themselves to maximize the external customer's satisfaction only. That is, they fail to consider that the resources needed to deliver a product or service are always constrained and that the actual costs allocated to each TA are also constrained. In brief, existing QFD researchers have not effectively considered the trade-off relationship between the quality and the cost under limited resources (Wasserman 1993; Bode, Fung 1998; Tang et al. 2002; Raharjo et al. 2006).

This study develops a system named the stochastic quality-cost optimization (SQCO) system, which implements the quality-cost optimization process in order to identify the trade-off between the project participants' conflicting interests involved in a design alternative (i.e. unitized metal curtain-wall unit (WBDG 1993). The system integrates QFD, MOGA, sensitivity analysis, and simulation using MOGA Toolbox in MATLAB)). It optimizes the external and internal customers' satisfaction by identifying the trade-off between the quality and cost of a design alternative. According to Peach (1997), there are external and internal customers. The construction owner who receives a constructed facility or project management service provided by the contractor is an external customer, while the higher management of the construction company who is responsible for achieving business success is an internal customer.

The research contributions are twofold. First, the House of Quality (HoQ) which computes the construction owner's and the contractor's satisfactions was modeled. Surveys were administered to construction owners (average 11.2 years of experience), architects as the independent assessors (average 15.6 years of experience), and contractors (average 16.7 years of experience) who are highly experienced in either curtain-wall design or installation on job sites. The Customer Requirements (CRs) and their importance weights, the relationship between Customer Requirements and Technical Attributes (TAs) of a curtain-wall unit, and the costs of the components of a curtain-wall unit were obtained from the three expert groups mentioned previously. The data obtained from the surveys were used as the QFD input to create the HoQ model. The HoQ model resolves the conflict of interest between the construction owner and the contractor who have keen interests in quality and cost, respectively. Second, an automated system that implements the HoQ was developed. The system called the stochastic quality-cost optimization (SQCO) system integrates QFD and multi-objective genetic algorithm (MOGA). It provides an optimization tool that identifies the optimal trade-off yielding maximum satisfaction for the construction owner and the contractor. The system is designed to complement the deficiencies of existing QFD applications as discussed in the previous sections. It considers the budget constraints, quantifies the satisfaction of construction owners and contractors, and identifies the optimal trade-off between the satisfaction of owners and contractors within the budget constraints specified in a contract. It also computes the optimal degree of planned achievement of the curtain-wall components, provides the optimal cost allocation to the curtain-wall components within the allowable budget, and determines the optimal solution that balances the conflicting interests by integrating QFD and MOGA. In addition, it provides a decision-maker with the variance of the project partici- 
pants' satisfactions when the cost allocations to curtainwall components change.

The research was conducted in six steps. First, the existing QFD studies that consider the cost aspect were investigated. Second, both the Customer Requirements (CRs) and Technical Attributes (TAs) involved in a curtain-wall unit were identified in a literature survey. Third, the surveys were administered to the three expert groups (i.e. construction owners, architects, and contractors) who were highly experienced in curtain-wall design; the data so collected (i.e. the relative importance weights of the customer requirements $\left(d_{i}\right)$, the relationships between customer requirements and technical attributes $\left(R_{i j}\right)$, and the correlations between the technical attributes $\left(T_{i j}\right)$, etc.) were used as the QFD input. Fourth, the HoQ model was designed using QFD to compute both parties' satisfactions for selecting the optimal curtain-wall design from several alternatives. In addition, an optimization method that identifies the optimal trade-off between quality and cost was integrated into the model. Fifth, an automated system was developed that integrates the HoQ model and the optimization method. Finally, the applicability of the new system was verified by carrying out a case study relative to selecting an optimum curtain-wall design with an in-depth discussion. The material in this paper is organized in the same order.

\section{Literature survey}

\subsection{Current state of existing QFD research studies that use cost}

Various decision making approaches for design alternative selection have been reported, i.e. optimization technique (Kracka et al. 2010; Oh et al. 2011; Suh et al. 2011; Cha et al. 2011), multi-criteria decision (Çelik et al. 2010; Wang 2011; Kanagaraj, Mahalingam 2011; Lee et al. 2012), life cycle cost analysis (Wang et al. 2010; Eamon et al. 2012), life cycle assessment (Du, Karoumi 2013), etc. However, few existing research provides quality-cost tradeoff analysis. Wasserman (1993) proposed the first QFD model that computes the priorities of Technical Attributes (TAs) by allocating a limited budget to respective TAs by calculating the ratio of Technical Importance $\left(\mathrm{w}_{k}\right)$ over the Cost Index $\left(\mathrm{c}_{k}\right)$. Bode and Fung (1998) advanced Wasserman's model by converting the primary costs used by Wasserman (1993) into actual costs using the correlation between TAs. These and other researchers recommended taking into account the cost dimension by integrating an approach that allocates a budget to each TA in proportion to the priorities of TAs. However, the existing approaches are limited because sometime insufficient cost is allocated to some of the TAs that have lower priority, hence making it difficult to attain design targets. In other words, most of the existing QFD models do not take resource constraints into account in designing products (Fung et al. 2002). To eliminate the discrepancies discussed previously, Fung et al. (2002) suggest a model that integrates a resource optimization method into the existing QFD using Genetic Algorithm (GA). The model searches the alternative cost allocations and selects the cost allocation that maximizes customer satisfaction within a limited budget. It introduces the concepts of planned attainment $\left(y_{i}\right)$ and actual attainment $\left(x_{i}\right)$ of TAs, and the concept of target attainment (i.e. satisfaction threshold, $\left.\theta_{0}=0.45\right)$ into QFD to quantify the level of customer satisfaction, and to assure that the actual attainments of all TAs always achieve more than the specific threshold. It searches for the set of planned attainments that maximizes the customer satisfaction using the following equation, $\left.O S\left(w^{*}, y\right)=\sum w^{*}{ }_{i} * y_{i}\right)$.

\subsection{Current state of existing QFD research studies in optimization}

Existing QFD research prioritizes the TAs of a product to maximize customer satisfaction. However, a design process involves multi-participants (i.e. construction owners and contractors) who have multi and/or conflicting objectives (e.g. minimizing cost, maximizing quality, minimizing technical difficulty, etc.). The objectives exert considerable influence on product quality and the possibility of delivering the product within budget. Several researchers have proposed optimization methods that reconcile these objectives originating from the project environment that surrounds the construction owner and the contractor who are external and internal customers, respectively. They claimed that it would be desirable to integrate reconciled objectives into designing QFD.

Wasserman (1993) introduced linear programming into QFD to find the optimal budget allocation. Tang et al. (2002) and Fung et al. (2002) integrated Genetic Algorithm (GA) into QFD to identify the optimal budget allocation for achieving maximum customer satisfaction and enterprise satisfaction. These are multi-objective optimization models that aim to satisfy both the customer and the enterprise by maximizing the quality performance and by minimizing the cost, respectively. As discussed previously, several researchers have integrated the availability of enterprise resources into QFD. However, none of the existing models integrate multi-objective optimization algorithm (Zitzler et al. 2011), sensitivity analysis, and simulation (Law, Kelton 2000) into QFD in a software application. A new system called SQCO, which is a cost-based QFD, is presented in this study for a viable solution to these issues.

\section{Stochastic quality-cost optimization system}

Detailed explanations of QFD that accounts for the cost dimension are provided in other publications (e.g. Wasserman 1993; Bode, Fung 1998; Tang et al. 2002). First, this section presents the detailed modelling steps relative to formulating the HoQ which computes the construction owner's satisfaction and the contractor's satisfaction involved in curtain-wall design alternatives. Second, the detailed steps relative to designing survey questionnaires and collecting data is presented. Third, the mathematical 
formulation relative to integrating MOGA and simulation with the HoQ is described.

\subsection{Integrating the cost dimension into $\mathrm{HoQ}$}

This section introduces the detailed steps by which the cost dimension is integrated into the HoQ for selecting an optimal curtain-wall design alternative. The cost-based HoQ defines the construction owner's requirements and engineering components (i.e. curtain-wall components) using the data obtained from the survey respondents. The cost-based HoQ differs from existing HoQ models (Wasserman 1993; Bode, Fung 1998; Tang et al. 2002) in that it facilitates collecting and processing QFD input data, encourages the utilization of the positive or negative correlations between engineering components (i.e. the curtain-wall components) defined in the roof of the HoQ, computes the construction owner's satisfaction and the contractor's satisfaction, and presents information relative to achievements (i.e. planned achievement and actual achievement) and cost (i.e. the primary cost, the actual cost, and the planned cost) in the HoQ. Figure 1 shows the cost-based HoQ that is designed to select an optimal curtain-wall design alternative. It contains information about owner requirements, the technical attributes of a curtain-wall unit, the strength of their interrelationship, and the correlation between the technical attributes. The definition of QFD input variables and the data processing to obtain QFD output data are presented below in detail:

- Column (1): It is the construction owner requirements (ORs) for a metal curtain-wall used in a tall building. The ten ORs listed in Table 1 were adapted from the document entitled "Building Envelope Design Guide - Curtain Walls" (WBDG 1993) which provides with up-to-date information on a wide range of building-related guidance, criteria and technology. The ten dimensions (i.e. 'thermal performance', 'moisture protection', 'visual', 'sound', 'safety', 'maintenance access', 'health and indoor air quality', 'durability and service life expectancy', 'maintainability and reparability', and 'sustainability') are described in Table 1.

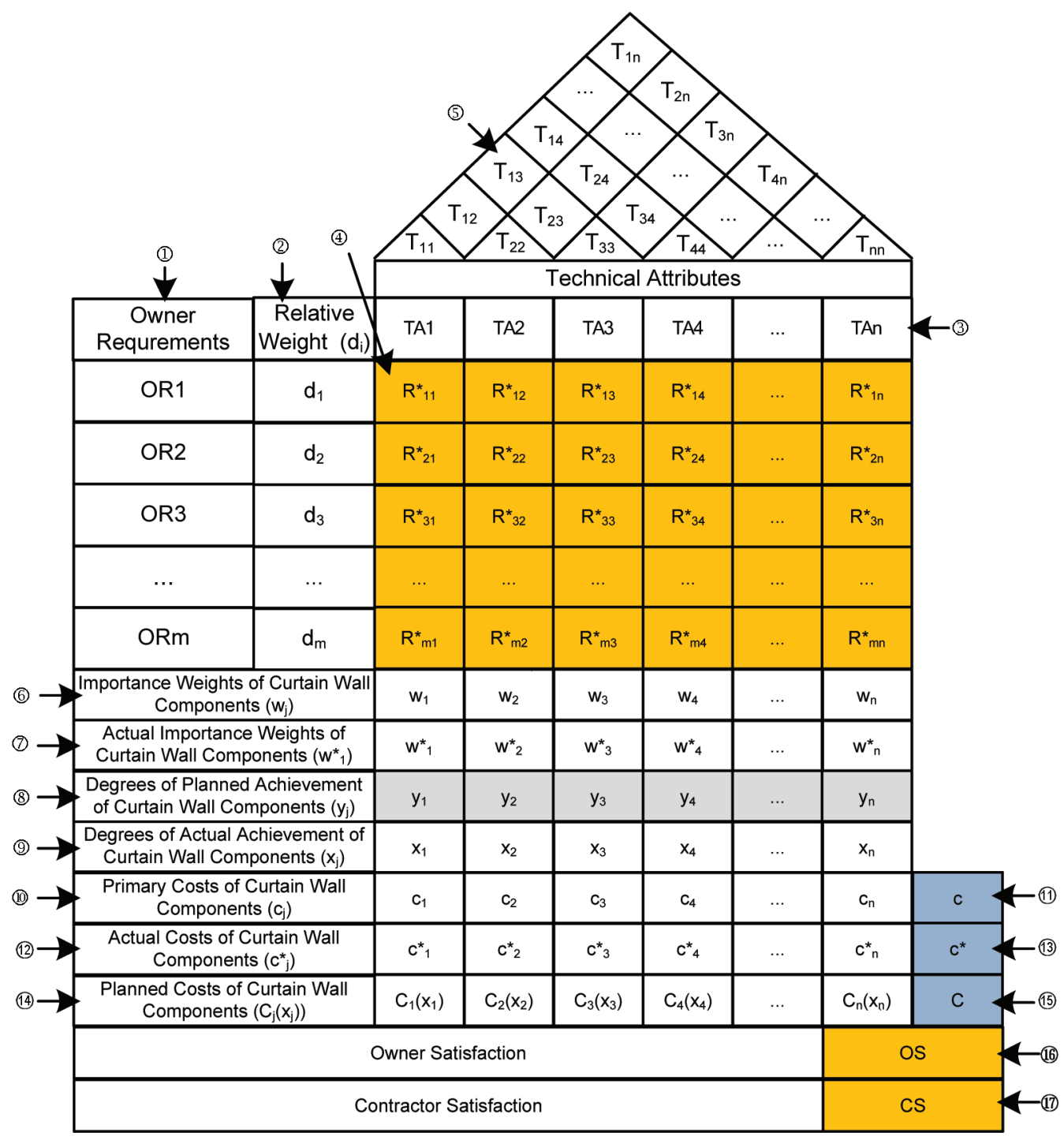

Fig. 1. The HoQ integrating cost dimension 
Table 1. Construction owner requirements for curtain-wall design (adapted from WBDG 1993)

\begin{tabular}{l|l}
\hline \multicolumn{1}{c|}{ Owner needs } & \multicolumn{1}{c}{ Definitions } \\
\hline Thermal performance & The thermal efficiency of a building relative to protecting thermal conduction and solar radiation. \\
\hline Moisture protection & The performance to protect water penetration and/or condensation. \\
\hline Visual & The performance to service day lighting and/or aesthetics. \\
\hline Sound & The performance to stop air leakage. \\
\hline Safety & The performance to slow fire and combustion gases between floors. \\
\hline Maintenance access & The performance to stabilize swing stage rigs used by maintenance and cleaning crews. \\
\hline $\begin{array}{l}\text { Health \& indoor air } \\
\text { quality }\end{array}$ & $\begin{array}{l}\text { The performance to protect air and water which can contribute to Indoor Air Quality (IAQ) problems } \\
\text { by supplying liquid water and condensation moisture for mold growth. }\end{array}$ \\
\hline $\begin{array}{l}\text { Durability \& service } \\
\text { life expectancy }\end{array}$ & $\begin{array}{l}\text { The performance to endure issues resulted in glazing problem, gaskets and sealants failure and to } \\
\text { maintain the system with a long usable life in economics. }\end{array}$ \\
\hline $\begin{array}{l}\text { Maintainability \& } \\
\text { repair-ability }\end{array}$ & $\begin{array}{l}\text { The ease and speed with which the system can be successfully repaired and/or restored to operational } \\
\text { status after the service life of each component (perimeter sealants, anodized frames) passes. }\end{array}$ \\
\hline Sustainability & The easiness to recycle the material (aluminum frame, glass) in the future. \\
\hline
\end{tabular}

- Column (2): This column includes the relative importance weights $\left(d_{i}\right)$ of the ten owner requirements(ORs). They were reported by construction owners in a questionnaire survey on a 9-point Likert scale where 1 is 'not important', and 9 is 'extremely important'.

- Row (3): This row includes the technical attributes (TAs) of the twelve components of a curtain-wall unit which were adapted from the standard drawings obtained from 'Building Envelope Design Guide Curtain Walls' (WBDG 1993). A curtain-wall unit that meets the construction owner's requirements consists of these engineering components which includes 'aluminum frames', 'exterior cover', 'anchor accessory', 'fire safe insulation', 'gaskets', 'vision glass', 'spandrel glass', 'seals', 'splice sleeve', 'index clip', 'glazing setting blocks', and 'back pan'. They were listed in the same order in the HoQ.

- Matrix (4): This matrix represents the normalized strength of the relationship $\left(R_{i j}^{*}\right)$ between the ten owner requirements (ORs: column (1)) and the twelve curtain-wall components (TAs: row (3)). This information was obtained from architects who have extensive experience in curtain-wall projects by means of a survey instrument on a 9-point Likert scale where 1 is 'no relation', and 9 is 'perfect (one-on-one) relation'. The information represents the contribution of a curtain-wall component to satisfy an individual owner requirement.

- Matrix (5): This matrix represents the correlation $\left(T_{j k}\right)$ between the $j^{\text {th }}$ and $k^{\text {th }}$ curtain-wall components (TAs: row (3)). If there is no dependence between them, $T_{j k}=0$; otherwise it represents the degree of dependence. This information was obtained from specialty contractors who have extensive experience in engineering, manufacturing, delivering and installing curtain-walls. The information is also obtained by means of a survey instrument on a 5-point Likert scale, where in the case of a positive correlation, 1 is 'very little correlation', and 5 is 'very high correlation'; conversely, in the case of a negative correlation, -1 is 'very little correlation', and -5 is 'very high correlation'.
- Row (6): This row represents the normalized importance weights $\left(w_{j}\right)$ of curtain-wall components. They represent the priority of each curtain-wall component calculated by using the relative importance weights of the owner requirements $\left(d_{i}\right)$ and the strength of the relationship between the construction owner requirements and the curtain-wall components $\left(R_{i j}\right)$ as shown in Eqn (1):

$$
w_{j}=\sum_{i=1}^{m} d_{i} R_{i j}^{*}, \mathrm{j}=1,2, \ldots, \mathrm{n},
$$

where: $R^{*}{ }_{i j}$ is obtained by normalizing the $R_{i j}$ matrix. $R_{i j}$ represents the degree to which the $j^{\text {th }}$ curtain-wall component (TA) contributes to satisfy the $i^{\text {th }}$ owner requirement (CR).

- Row (7): This row includes the actual importance $\left(w_{j}^{*}\right)$ of curtain-wall components. This is calculated using the correlation between the curtain-wall components $\left(T_{i j}\right)$ available in Matrix (5) and the normalized importance weights of curtain-wall components $\left(w_{j}\right)$ available in row (6) according to Eqn (2). Obviously, the actual importance $\left(w_{j}^{*}\right)$ of curtain-wall components are calculated by taking into account the correlations between TAs:

$$
w_{j}^{*}=\sum_{k=1}^{j-1} T_{k j} w_{k}+\sum_{k=j}^{n} T_{j k} w_{k} .
$$

- Row (8): This row represents the degree of the planned achievement $\left(y_{j}\right)$ of curtain-wall components. This is defined as the design targets to be fulfilled on the assumption that there are no dependencies among curtain-wall components. The twelve curtain-wall components in Row (3) have different degrees of planned achievement $\left(y_{j}\right)$ which are the inputs of the two objective functions relative to owner satisfaction (OS) and contractor satisfaction (CS). Given the two sets of information, i.e. the QFD input data $\left(d_{i}, R_{i j}^{*}, T_{j k}, c_{j}\right)$ obtained from expert groups and the project specific constraints (e.g. allowable budget, the degree of the actual achievement), the 
optimal degrees of the planned achievement which maximizes the two objective functions are computed using MOGA. A discussion of the primary cost $\left(c_{j}\right)$ of curtain-wall components is presented in Row (10). Detailed explanations of the optimization system employing MOGA is also presented in a later section.

- Row (9): The information in Row (9) represents the degree of the actual achievement $\left(x_{j}\right) \cdot x_{j}$ are calculated by using the degree of planned achievement $\left(y_{j}\right)$ of curtain-wall components obtained by employing MOGA as presented in Row (8) and the correlation between the curtain-wall components $\left(T_{j k}\right)$ available in Matrix (5), the roof of $\mathrm{HoQ}$, according to Eqn (3):

$$
x_{j}=\sum_{k=1}^{j-1} T_{k j} y_{k}+\sum_{k=j}^{n} T_{j k} y_{k} .
$$

- The degree of the actual achievement $\left(x_{j}\right)$ represents the cost effect attributed to the dependency relationships between the curtain-wall components $\left(T_{j k}\right)$, when enough costs are allocated to curtainwall components in proportion to the degree of the planned achievement $\left(y_{j}\right)$ of the components. For example, given that $T_{12}, T_{13}, y_{1}, y_{2}$, and $y_{3}$ are $0.05,-0.01,0.7,0.5$, and 0.8 , respectively, $x_{1}$ is calculated as follows; $x_{1}=1 * y_{1}+T_{12} * y_{2}+T_{13} *$ $y_{3}=1 * 0.7+0.05 * 0.5+(-0.01) * 0.8=0.717$. Originally, the degree of the planned achievement of component $1\left(y_{1}\right)$ is 0.7 . However, the degree of the actual achievement of component $1\left(x_{1}\right)$ increases to 0.717 due to the correlation between the curtainwall components. In this case, the degrees of the actual achievement are greater than the degrees of the planned achievement due to the correlation between the curtain-wall components, even though the degrees of the planned achievement are set lower than the design target (i.e. the degrees of the actual achievement) in the initial stage of QFD planning. The degrees of the actual achievement are used as a constraint of this optimization problem using GA.

- Row (10): This row represents the primary cost $\left(c_{j}\right)$ of curtain-wall components which is required to deliver each of the components independently, assuming that there are no technical dependencies among curtain-wall components. Given the standard drawings of a curtain-wall provided by WBDG (1993), the cost information was collected from experts in curtain-wall design and cost estimation.

- Cell (11): This cell represents the sum $(c)$ of the primary costs of curtain-wall components $\left(c_{j}\right)$. It is the total cost to be committed to a curtain-wall unit when the dependencies among the curtain-wall components are not considered.

- Row (12): This row represents the actual costs $\left(c^{*}\right)$ of curtain-wall components which are adjusted from the primary costs of curtain-wall components. A specific curtain-wall component has neighbour component(s) which may have technical depend- encies with the specific component. The neighbour component(s) contributes to achieve the design target of the specific curtain-wall component due to the technical dependency. The actual costs are calculated using the achievement degrees of neighbour components involved in the specific component and the technical dependency, according to Eqn (4):

$$
c_{j}^{*}=c_{j} \times\left[1-\left(\sum_{k=1}^{j-1} T_{k j} y_{k}+\sum_{k=j+1}^{n} T_{j k} y_{k}\right)\right] .
$$

- The actual costs are used to calculate the planned cost (refer to Row (14)) using the degrees of the actual achievement $\left(x_{j}\right)$ in Row (9) which represent the amount of influence attributed to the neighbour components. For example, given that $\left[c_{1}, T_{12}, T_{13}, y_{2}\right.$, and $\left.y_{3}\right]$ are $[100,0.05,-0.01,0.5$, and 0.8$]$, respectively, the actual cost of component $1\left(c^{*}{ }_{1}\right)$ is calculated as: $c_{1} *\left[1-\left(T_{12} * y_{2}+T_{13} * y_{3}\right)\right]=100 *[1-(0.05 * 0.5+$ $(-0.01)^{* 0.8)]}=\$ 98.3 . c^{*}{ }_{1}$ is less than the primary cost of component $1\left(c_{1}\right)$ of $\$ 100$. The cost saving of $\$ 1.7(=\$ 100-\$ 98.3)$ is contributed by the technical dependency among the neighbouring components.

- Cell (13): This cell represents the sum total $\left(c^{*}\right)$ of the actual costs of a curtain-wall component $\left(c^{*}{ }_{j}\right)$. It is the total cost of a curtain-wall unit when the dependencies among the curtain-wall components are considered. It is obtained by adjusting the primary costs of components according to the technical dependencies among the curtain-wall components.

- Row (14): This row represents the planned costs $\left(C_{j}\left(x_{j}\right)\right)$ calculated using the actual costs (Eqn (4)) and the degrees of the actual achievement (Eqn (3)) according to Eqn (5). These are the costs demanded to produce the components of a curtain-wall unit:

$$
C_{j}\left(x_{j}\right)=c^{*}{ }_{j} x_{j} .
$$

- Cell (15): This cell represents the sum total of planned costs of all components (C) which is the unit cost of a curtain-wall.

- Cell 16): This cell represents the owner satisfaction (OS) which is obtained from the objective function formulated using the normalized importance weight of curtain-wall components $\left(w_{j}\right)$ and the degree of the actual achievement $\left(x_{\mathrm{j}}\right)$ using Eqn (6):

$$
O S=\sum_{j=1}^{n} w_{j} x_{j}=\sum_{j=1}^{n} w_{j}^{*} y_{j} .
$$

- Cell 17): This cell represents the contractor satisfaction (CS) which is obtained from the objective function formulated using the unit cost of a curtain-wall given in Cell (15) as shown in Eqn (7). $C S$ is inversely proportional to the unit cost $(C)$ in Cell (15). ontractor satisfaction decreases as net profit decreases; it similarly decreases as unit cost $(C)$ increases. $O S$ is inversely proportional to $C S$, and vice versa: 


$$
C S=\left\{\begin{array}{cl}
1 & , C \leq C_{0} \\
\left(1-\alpha_{0}\right)\left(\frac{B-C}{B-C_{0}}\right)^{r}+\alpha_{0} & , C_{0}<C \leq B, \\
0 & , C>B
\end{array}\right.
$$

where: $C$ is the total planned cost; $C_{0}$ is the minimum planned cost; $B$ is the allowable budget; $\alpha_{0}$ is the satisfaction with total budget committed; and $r$ is the coefficient of curve shape.

\subsection{The design of survey questionnaires}

The project participants who have conflicting interests in identifying an optimal curtain-wall design alternative in $\mathrm{D} / \mathrm{B}$ construction are identified based on their role, responsibilities, needs and expectations as: (1) construction owners; (2) architects; and (3) contractors, three sets of questionnaires were therefore prepared and administered to these three populations.

A survey questionnaire was administered to all 63 construction owners and/or the owner's representative of $\mathrm{D} / \mathrm{B}$ construction listed in the database of the Seoul metropolitan government. The rate of response was $33.33 \%$. Then, the weights were normalized using the mean value of the survey data. The questionnaire sought information about the following:

- The demographics of construction owners: this information was expressed in terms of organization type (all were involved in $\mathrm{D} / \mathrm{B}$ projects), years of experience in the industry (on the average 11.2 years), job title of the respondents (higher executives such as President, Vice President, and Director of Public Works), and project type (mostly building construction).

- The relative importance weights of the ten owner requirements: this information was sought for use in House of Quality calculations. The values assigned by the owners were later normalized (refer to Matrix 1 in later section). The ten owner requirements (ORs) are defined in Table 1. These requirements were adapted from the factors documented in WBDG's (1993).

A survey questionnaire was administered to all 140 architects who had experience with D/B construction and registered in the database of the Korean Institute of Registered Architects (KIRA). The rate of response was 19.29\%. The questionnaire sought information about the following:

- The demographics of architects: this information was expressed in terms of years of experience in the industry (average 15.6 years of experience), job title of the respondents (presidents and vice presidents), and project type (mostly building construction).

- The strength of the relationship between the ten owner requirements (ORs) and the twelve curtain-wall components (TAs): this information was obtained from architects who have extensive experience in curtain-wall projects by means of a survey in- strument on a 9-point Likert scale where 1 is "no relation', and 9 is 'perfect (one-on-one) relation'. The values assigned by the architects were normalized (refer to Matrix 2 in later section). The information represents the contribution of a curtain-wall component to satisfy an individual owner requirement.

A survey questionnaire was administered to all 128 curtain-wall specialty contractors who are highly experienced in either curtain-wall design or installation on job sites and registered in the database of the Korean Specialty Contractor Association (KOSCA). The rate of response was $17.19 \%$. The questionnaire sought information about the following:

- The demographics of specialty contractors: this information was expressed in terms of years of experience in the industry (average 16.7 years of experience), and job title of the respondents (presidents and vice presidents).

- The correlation between the curtain-wall components (TAs): This information was obtained from specialty contractors who have extensive experience in engineering, manufacturing, delivering and installing curtain-walls. It is also obtained by means of a survey instrument on a 5-point Likert scale, where in the case of a positive correlation, 1 is 'very little correlation', and 5 is 'very high correlation'; conversely, in the case of a negative correlation, -1 is 'very little correlation', and -5 is 'very high correlation'. The values assigned by the specialty contractors were normalized (refer to Matrix 3 in later section).

An estimate was administered to a professional estimator who has extensive experience in estimating curtain-walls. This type of respondent is hard to come by, as professional estimator having extensive experience in estimating curtain-walls is a rare occurrence. This person was the representative of one of the largest curtainwalls specialty contractor in Korea. This company has been in existence since 1975, has specialized expertise in design, engineering and construction of curtain-wall, has certified with ISO 9001 and ISO 14001, and has operated nationally and internationally in Korea and other countries. The person who engaged in estimating was fully familiar with D/B projects. The information obtained included the cost estimates of twelve curtain-wall components. Given the standard drawings of a curtainwall provided by WBDG, the cost that is required to deliver each of the components independently was collected from the expert. It was assumed that there are no technical dependencies among curtain-wall components. The costs allocated by the expert were assigned to Matrix 4 which is presented in later section.

\subsection{Integrating multi-objective genetic algorithm into $\mathrm{HoQ}$}

Genetic Algorithm (GA) is inspired by the mechanics of evolutions and is an optimization method that assists 
decision makers to identify optimal or near-optimal solutions for problems with a large search space. It adopts the concept of the survival of the fittest and structures the exchange of genetic materials among populations over successive generations as a basic mechanism for the search process (Goldberg 1989). Given several conflicting objective functions, multi-objective GA finds a Pareto optimal solution. The Pareto optimal solution is accepted as the most dominant and the best solution of all the non-dominant solutions produced by the conflicting objective functions (El-Rayes, Kandin 2005; Cha et al. 2011).

The multi-objective genetic algorithm (MOGA) is integrated into the QFD model to search for the Pareto optimal or near optimal trade-off between quality and cost in this study. The algorithm sorts the individuals in descending order according to the Pareto optimal rank and selects the individual at the top of the list. If multiple individuals are at the top of the list, the crowding distances are computed. The individual having the lowest crowding distance is selected as a parent to generate a child in the next generation (Deb 1999, 2001). The project participants (i.e. the construction owners and the contractors) have conflicting interests in selecting the optimal design alternative for a curtain-wall unit. The construction owner expects to maximize the quality of the curtain-wall unit by encouraging the contractor to use costly materials/processes, while the contractor expects to minimize the cost of the curtain-wall unit by seeking less costly solutions from the specialty contractor. Therefore, selecting the optimal design alternative is equivalent to finding the optimal balance between owner satisfaction $(O S)$ and contractor satisfaction $(C S)$ relative to the quality and the cost of the curtain-wall unit by picking the most appropriate combination of planned achievement of curtain-wall components.

Given a set of planned achievements of curtainwall components (refer to row (8) in Fig. 1) as a design target, SQCO automatically calculates QFD outputs such as actual achievement, planned cost, construction owner satisfaction, and contractor satisfaction. SQCO has optimization capability to address the trade-off between the conflicting interests of the project participants. The system operates in three steps, namely: (1) defining the objective functions, (2) defining the constraints, and (3) implementing multi-objective genetic algorithm.

The first step, i.e. defining the objective functions, involves formulating the two objective functions (i.e. $O S$ and $C S$ ) shown in Eqns (6) and (7). $O S$ and $C S$ are computed using decision variables such as actual achievement and planned cost, which are calculated using the planned achievement $\left(y_{j}\right)$. The system searches the optimal curtain-wall design alternative that maximizes the two objective functions simultaneously. Selecting the optimal curtain-wall design alternative is equivalent to searching the optimal chromosome of planned achievements $\left(y_{j}\right)$ that maximizes the two objective functions (i.e. Eqns (6) and (7)) simultaneously.

The second step, i.e. defining the constraints, involves identifying and formulating the constraints that are specified in the contract. The constraints are project specific because: (1) the actual achievement of curtain-wall components should be obtained over a specific satisfaction threshold (i.e. X\%; Tang et al. 2002). X varies within the $[0,100]$ range; (2) the budget of a curtain-wall unit is constrained to a certain value (e.g. $\$ 600 /$ unit) specified in the contract; (3) the planned costs of curtain-wall components should be positive values; and (4) the internal QFD variable should also be constrained. Generally, most studies that make use of Genetic Algorithms (GA) limit only the range of the decision variables. However, SQCO produces a set of internal QFD data (i.e. actual achievement, planned costs, etc.) during QFD computation. The internal QFD data are returned to the QFD to calculate QFD outputs (i.e. $O S, C S$, the total planned cost (C), etc.). Not only the decision variables, but also the internal QFD variables should be constrained. It is worth noting that QFD may reach unrealistic solutions (e.g. negative planned cost, planned achievement exceeding $100 \%$, etc.) if the ranges of the internal QFD variables are not appropriately constrained. SQCO introduces the concept of penalty into the fitness functions of GA to remove unrealistic solutions from GA experiments. By setting the range of the internal QFD variables, SQCO ensures that the search for the optimum solution is secured. If the internal QFD data do not satisfy the constraints initially set by the user, the corresponding individual who does not satisfy the constraints would be excluded from the list of the fittest individuals because this individual's fitness value would be reduced by SQCO. Computing owner satisfaction $(O S)$, which is one of the objective functions in the GA experiment, the original fitness value is reduced by subtracting the penalty as shown in Eqn (8):

$$
\begin{aligned}
& O S=\sum_{j=1}^{n} w_{j}^{*} \times y_{j} \\
& I F\left(0.45>x_{j}\right) \text { or }\left(1<x_{j}\right) \text { or }\left(0>C_{j}\right) \\
& \quad O S=O S-P \\
& \text { ELSE } \quad \text { OS }=\text { OS } \\
& \text { END }
\end{aligned}
$$

where: $O S$ - construction owner's satisfaction; $y_{j}$ - the degree of the planned achievement; $w_{j}{ }_{j}$ - actual technical importance; $C_{j}$ - planned cost; $P$ - penalty.

If an internal QFD variable does not satisfy the constraints initially set (i.e. the degree of the actual achievement $\left(x_{j}\right)$ should be within the $[0,1]$ range and the planned cost $\left(C_{j}\right)$ should be a positive value), the individual's fitness value would be reduced by an amount equal to penalty $(P)$ as shown in Eqn (8) when computing the owner's satisfaction $(O S)$. In this way, the probability that the individual is selected in the next generation would be reduced. 
The third step, i.e. implementing the multiobjective genetic algorithm (MOGA), involves applying MOGA to select the optimal curtain-wall design alternative. This step operates in a successive series of four modes, namely: (1) importing the QFD input and initializing GA options; (2) evaluating the fitness of the construction owner's satisfaction and the contractor's satisfaction; (3) generating populations and identifying the fittest individual over successive generations; and (4) analysing the QFD output. The method described below was coded into an automated system by using MAT$\mathrm{LAB}$ programming. The algorithm of SQCO is presented in Figure 2 with detailed descriptions as follows.

The first mode, i.e. importing the QFD input and initializing GA options, involves importing the QFD input from a database that contains data collected from expert groups using a survey questionnaire; it also involves identifying the optimal set of GA options. The mutation rate increases by an interval of 0.1 as expressed in Step (1) while holding the crossover rate, and vice versa. GA repeats Steps (2) to (14) for each set of the mutation/crossover rate combinations. The best set of crossover and mutation rates is identified from the experiments. Actually, a very common mode of the GA experiment is to make a single GA run of somewhat arbitrary options (i.e. initial population, mutation and crossover rates, stopping rules, etc.) and then to treat the resulting GA outputs as the 'true' characteristic of the model. Because GA typically relies on random number generation in the execution of the algorithm based on the initial options, the corresponding GA outputs are only particular realizations of random variables that may be a local solution. Therefore, it is not appropriate to assume that the solution obtained from a single GA run is the 'true' optimal solution. The QFD input including construction owners' requirements, their relative importance weights, the relationships between construction owners' requirements and curtain-wall components, the correlations between the components, and the set of primary costs (or unit costs) of the components are imported from a database that contains data collected from expert groups using a survey questionnaire in Step (2). The GA options (i.e. number of generations, population size, crossover rate, mutation rate, and stopping rules, etc) are specified in Step (3) for initializing the GA experiments. The number of decision variables (i.e. the length of a chromosome) is 12 , because the planned achievement corresponds to the 12 components of a curtain-wall unit. Because the GA options contribute to the reliability of the GA output, the optimal number of generations and the population size ensure the quality of the solution based upon the length of a chromosome (El-Rayes, Kandin 2005). The mutation and crossover rates were also identified using sensitivity analysis. The GA stopping rule was set using the maximum number of generations and the cumulative changes in the fitness value over generations. The GA stops if the number of iterations reaches the maximum number of generations or the minimum tolerance. If the difference of the fitness values obtained from previous and current best solutions is less than the minimum tolerance (i.e. the default value was set at $1.0 \mathrm{e}-3$ in this study), the algorithm stops. The random initial population was generated at the first generation in Step (4). The solutions of the initial population represent the optimal set of the planned achievement relative to the 12 curtain-wall components. The initial range of the solutions was set at $[0,1]$, because the planned achievement of the 12 curtain-wall components are normalized within $[0,1]$ values.

The second mode, i.e. evaluating the fitness of the construction owner's satisfaction and the contractor's satisfaction, starts by selecting feasible solutions from the solutions obtained in the previous mode to search an optimal set of planned achievements $\left(y_{j}\right)$ and to reproduce enhanced solutions. A feasible solution $\left(S_{n}\right)$ is selected from the initial population considered in Step (5). Owner satisfaction $(O S)$ and contractor satisfaction $(C S)$ for a feasible solution $\left(S_{n}\right)$ in a generation are calculated using the two objective functions shown in Eqns (11) and (12), respectively in Step (6). They are calculated using the sets of planned achievements, which are QFD input variables. SQCO utilizes a facility function called "GAMULTIOBJ" in MATLAB to search for an optimal set of planned achievements that maximize the two objective functions (i.e. OS and CS) simultaneously. GA identifies an individual that has the smallest value of the fitness function as the fittest in the generation. The fitness value of an individual is the value of the fitness function for that individual. But SQCO maximizes two objective functions. Therefore, the maximization problem was converted to a minimization problem by changing the original objective function (or fitness function), $\mathrm{f}(x)$ to $-\mathrm{f}(x)$. The fitness value of an individual is recalculated in Step (7) only if an internal QFD variable is not free from the constraints that are involved in the actual attainment $\left(x_{i}\right)$ obtained from QFD computation using the feasible solution selected in Step (5), and the planned cost $\left(C_{j}\right)$ of curtain-wall component as shown in Figure 1. The fitness determines the likelihood of the survival and reproduction of each solution in successive generations at Step (8). The algorithm checks if the current number of individuals is greater than the number of individuals in the population set at the outset in Step (3). This step repeats from (5) to (8) as many times as the number of the individuals in the population, based on string size as recommended by El-Rayes and Kandil (2005).

The third mode, i.e. generating populations and identifying the fittest individual over successive generations, starts by calculating the Pareto optimal rank and crowding distance of each solution $\left(s_{n}\right)$ in the parent population $\left(P_{g}\right)$ in Step 10. The Pareto rank is determined by ranking the fitness values of solutions in descending order according to how much a solution dominates other feasible solutions. A solution is identified as dominant when the solution has the least fitness value compared to other solutions. The fittest individual is the individual that maximizes the quality and mini- 


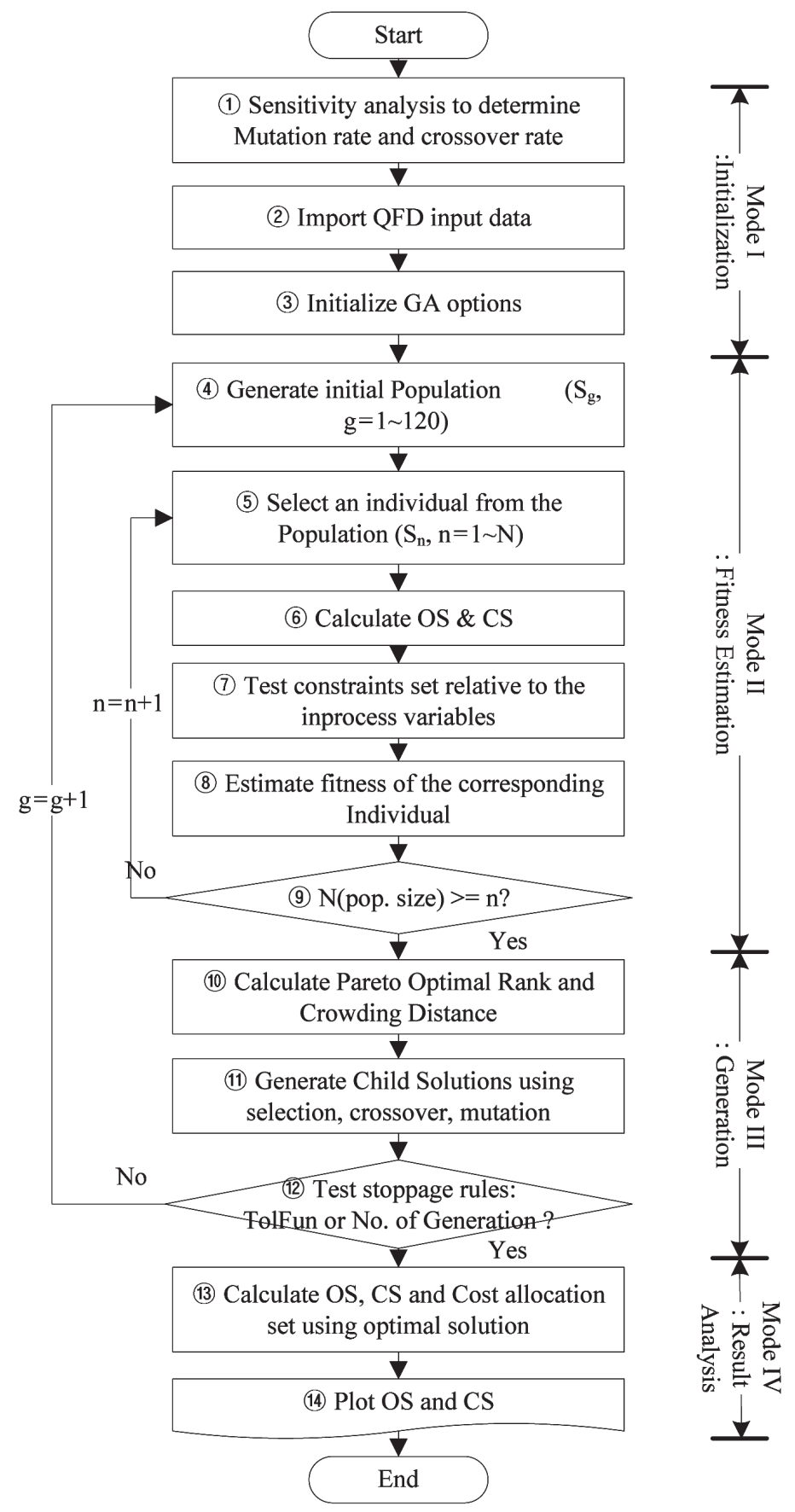

Fig. 2. Curtain-wall Quality-Cost optimization algorithm

mizes the cost simultaneously. The crowding distances among solutions represent the closeness of neighbor solutions to the solution under consideration. They represent the degree to which the solutions are scattered over a Pareto optimal front. When the crowding distance of a solution becomes large, the obtained solutions are widely spread over a Pareto optimal front and the diversity of solutions is secured (Deb 2001). Using the Pareto rank and crowding distance, the algorithm always selects the fittest solutions from the parent population $\left(S_{g}\right)$ and reuses them to generate child populations $\left(S_{g+1}\right)$ using the dominant solutions obtained from the parent population $\left(S_{g}\right)$ in Step (11). The algorithm applies selection, crossover, and mutation operators to the dominant solutions. The selection operation chooses the individuals that have higher optimal rank and wider crowing distance for reproduction. The crossover operation crosses each pair of the selected individuals at a randomly determined point. It reproduces two new children by swapping the genes (i.e. variables) coded in the chromosome (i.e. string) at this point. The mutation operation randomly changes the value of one of the variables in the string to induce innovation and to prevent premature convergence to local optima (Goldberg 
1989). The system checks if the GA experiment passes the maturity test in Step (12). It checks if the stopping rules set at Step (3) are met. If any of the stopping rules are met, the algorithm proceeds to Step 13); otherwise it returns to Step (4) and continues implementing the algorithm.

The fourth mode, i.e. analysing the QFD output, makes use of the best set of crossover and mutation rates identified in the sensitivity analysis conducted in Step (1) in order to find the optimum solutions converged, i.e. the optimal sets of planned achievements specified in Step (13). In addition, construction owner satisfaction, contractor satisfaction, planned costs of curtain-wall components, and total cost are calculated and saved in the computer's memory. Then, the GA output obtained from this experiment is accepted as the optimal global solution. The GA output calculated in Step (13) is plotted and the optimal quality-cost trade-off point is identified in Step (14).

\section{Test case}

An optimal curtain-wall design alternative was selected in this case study in order to demonstrate the procedure described in the preceding section and to illustrate the potential of SQCO in the context of multi participant decision-making. This section illustrates how the system identifies the optimal trade-off between the satisfaction of the construction owner and of the contractor simultaneously, and how it selects an optimal design alternative that allocates the allowable budget to the curtain-wall components in a way that optimizes the quality and cost of the design alternative. An executable of SQCO can be obtained upon request to the author.

To establish a HoQ, QFD input (i.e. the relative importance weights of the construction owner needs (refer to Matrix 1), the relationships between owner needs and curtain-wall components (refer to Matrix 2), the correlations between curtain-wall components (refer to Matrix 3 ), and the primary costs of curtain-wall components (refer to Matrix 4), etc.) were collected by means of a survey administered to construction owners (information in Matrix 1), architects (information in Matrix 2), curtain-wall design experts (information in Matrix 3), and contractors (information in Matrix 4).

Matrix 1:

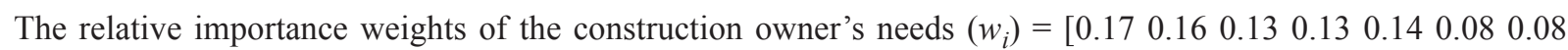
0.050 .050 .01 ].

Matrix 2:

The relationships between owner needs and curtain-wall components $\left(R_{i j}\right)=$

$\left[\begin{array}{llllllllllll}0.09 & 0.09 & 0.02 & 0.09 & 0.09 & 0.12 & 0.02 & 0.09 & 0.12 & 0.09 & 0.07 & 0.09 \\ 0.07 & 0.02 & 0.02 & 0.22 & 0.22 & 0.00 & 0.07 & 0.12 & 0.07 & 0.00 & 0.07 & 0.10 \\ 0.12 & 0.07 & 0.07 & 0.07 & 0.12 & 0.07 & 0.10 & 0.10 & 0.10 & 0.12 & 0.02 & 0.02 \\ 0.08 & 0.14 & 0.06 & 0.06 & 0.14 & 0.08 & 0.11 & 0.03 & 0.08 & 0.00 & 0.11 & 0.11 \\ 0.15 & 0.12 & 0.03 & 0.03 & 0.03 & 0.03 & 0.12 & 0.15 & 0.09 & 0.09 & 0.15 & 0.03 \\ 0.03 & 0.14 & 0.03 & 0.03 & 0.03 & 0.08 & 0.11 & 0.08 & 0.11 & 0.11 & 0.11 & 0.14 \\ 0.14 & 0.08 & 0.03 & 0.08 & 0.11 & 0.14 & 0.06 & 0.08 & 0.08 & 0.06 & 0.03 & 0.11 \\ 0.08 & 0.08 & 0.08 & 0.13 & 0.03 & 0.11 & 0.11 & 0.13 & 0.11 & 0.03 & 0.05 & 0.08 \\ 0.11 & 0.11 & 0.04 & 0.11 & 0.04 & 0.11 & 0.15 & 0.04 & 0.00 & 0.00 & 0.19 & 0.11 \\ 0.10 & 0.17 & 0.17 & 0.10 & 0.03 & 0.10 & 0.10 & 0.10 & 0.10 & 0.00 & 0.00 & 0.03\end{array}\right]$

Matrix 3:

The correlations between the curtain-wall components $\left(T_{j k}\right)=$

$\left[\begin{array}{llllllllllll}1.00 & 0.05 & -0.17 & 0.17 & 0.17 & 0.00 & 0.20 & 0.00 & 0.00 & 0.20 & 0.20 & 0.00 \\ 0.05 & 1.00 & 0.00 & 0.00 & 0.00 & 0.10 & 0.00 & 0.03 & 0.00 & 0.10 & 0.00 & 0.03 \\ -0.17 & 0.00 & 1.00 & 0.17 & -0.05 & 0.10 & 0.00 & 0.03 & -0.02 & 0.03 & 0.10 & 0.00 \\ 0.17 & 0.00 & 0.17 & 1.00 & 0.02 & 0.02 & -0.03 & 0.01 & 0.02 & 0.01 & 0.02 & 0.00 \\ 0.17 & 0.00 & -0.05 & 0.02 & 1.00 & 0.10 & 0.03 & 0.03 & 0.00 & 0.10 & -0.05 & 0.05 \\ 0.00 & 0.10 & 0.10 & 0.02 & 0.10 & 1.00 & 0.01 & 0.02 & 0.03 & 0.01 & 0.01 & 0.03 \\ 0.20 & 0.00 & 0.00 & -0.03 & 0.03 & 0.01 & 1.00 & 0.17 & 0.17 & 0.00 & 0.02 & 0.02 \\ 0.00 & 0.03 & 0.03 & 0.01 & 0.03 & 0.02 & 0.17 & 1.00 & 0.02 & 0.01 & -0.03 & 0.03 \\ 0.00 & 0.00 & -0.02 & 0.02 & 0.00 & 0.03 & 0.17 & 0.02 & 1.00 & 0.01 & 0.02 & 0.03 \\ 0.20 & 0.10 & 0.03 & 0.01 & 0.10 & 0.01 & 0.00 & 0.01 & 0.01 & 1.00 & 0.01 & 0.01 \\ 0.20 & 0.00 & 0.10 & 0.02 & -0.05 & 0.01 & 0.02 & -0.03 & 0.02 & 0.01 & 1.00 & 0.01 \\ 0.00 & 0.03 & 0.00 & 0.00 & 0.05 & 0.03 & 0.02 & 0.03 & 0.03 & 0.01 & 0.01 & 1.00\end{array}\right]$

Matrix 4:

The primary costs of curtain-wall components $\left(C_{j}\right)=\left[\begin{array}{llllllllllll}100 & 40 & 50 & 30 & 60 & 90 & 80 & 30 & 50 & 20 & 30 & 70\end{array}\right]$. 
Several constraints are set up as follows. The actual achievement $\left(x_{j}\right)$ of a component should exceed $45 \%$, the budget of a curtain-wall unit is limited to $\$ 500 /$ unit given that the total primary costs are identified as $\$ 650$ in this test case, the minimum contractor satisfaction $\left(\alpha_{0}\right)$ should be $45 \%$ when the budget is expended, the minimum budget of a curtain-wall unit is $\$ 300$, and the coefficient of the contractor satisfaction function $(r)$ is 1 . The project specific constraints were set by the system user.

Assuming that GA computes to two decimal places, the number of combinations of the planned achievements, that is, the possible number of planned costs of curtainwall components, is $100^{12}$ because a curtain-wall unit consists of 12 components and there are 100 possible values for gene (i.e. planned achievement for a component varies within the $[0,1]$ range in increments of 0.01 .). Because it is time-consuming to iteratively and exhaustively compute all the cases, MOGA was used to significantly reduce the searching time over the large solution spaces by excluding dominated solutions in the succeeding generations and by using the Pareto optimal rank and the crowding distance.

To identify optimal mutation and crossover rates, an automated sensitivity analysis was performed using the system. Setting the options (i.e. mutation rate, crossover rate, stopping rules, etc.) greatly affects the searching performance of a GA experiment over the solution spaces and the reliability of the solution obtained from it. In order to ensure that the solution obtained from the GA experiment is a global solution, sensitivity analysis was performed by incrementing the mutation rate in the range of $[0,1]$ by increments of 0.1 while holding the crossover rate constant, and vice versa as shown in Figure 4. The GA output (i.e. construction owner satisfaction, contractor satisfaction, and allowable budget) is plotted (the two satisfaction indices against allowable budget). These plots represent the optimal trade-off that maximally satisfies the two project participants within the corresponding allowable budget. The system automatically identifies

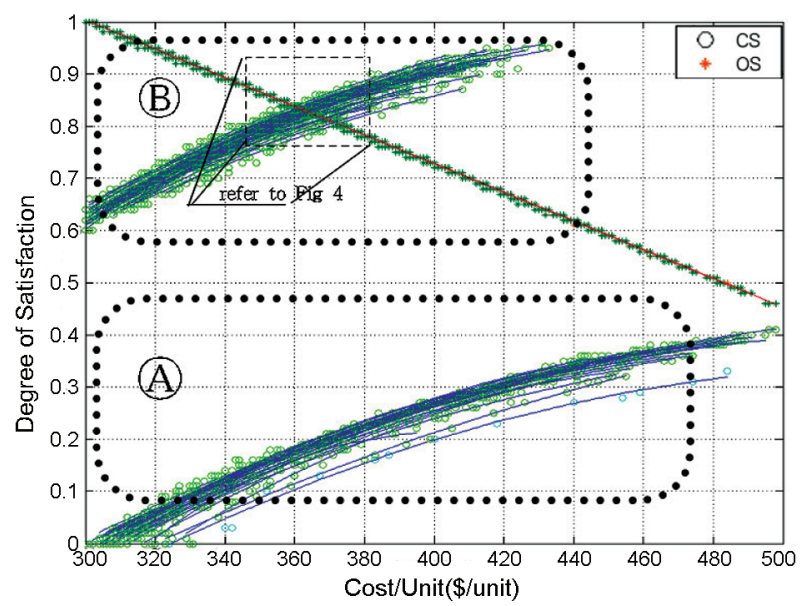

Fig. 3. Trade-offs according to the varying mutation and crossover rates

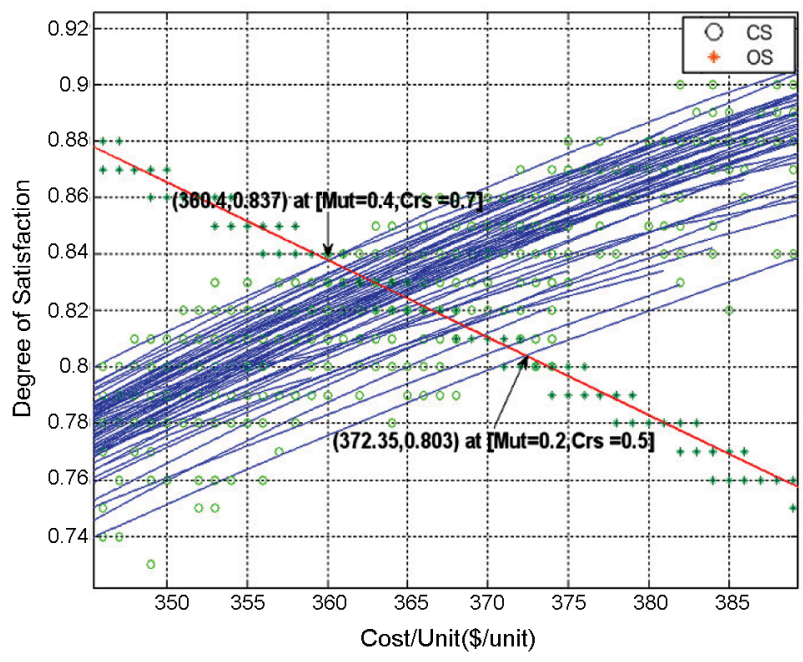

Fig. 4. Zoom-in view of the dotted box in Figure 3

the fittest individual by using the optimal mutation and crossover rates found.

The plot shown in Figure 3 (A) represents the local solutions obtained from one pair of mutation and crossover rates, whereas the plot shown in Figure 3 (B) represents the global solution obtained from another pair of mutation and crossover rates. The pair of optimal mutation and crossover rates is identified by computing the exact trade-offs of all mutation and crossover rates combinations iteratively. The theoretical objective functions are established by using regression analysis. Because GA produces discrete optimal solutions, the exact trade-off was calculated by executing curve fitting onto the plot that accommodates the objective functions. It is confirmed that the automated sensitivity analysis contributes to identify the appropriate mutation and crossover rate that results in the global solution. Figure 4, which is the zoom-in view of Figure 3 B, shows the solutions obtained when specific pairs of mutation and crossover rates were applied. The selected pair of optimal mutation and crossover rates is the one that has an intersection with the maximum degree of satisfaction and the minimum cost. The contractor satisfaction $(C S)$ function is assumed to be linear in regression analysis when evaluating the dominance of the pair of mutation and crossover rates.

The optimal global solution was identified using sensitivity analysis as follows. Given the mutation and crossover rates of 0.4 and 0.7 , the optimal global solution is found at the intersection of the two satisfactions (i.e. $O S$ and $C S$ ) where satisfaction and total unit cost are $83.7 \%$ and $\$ 360.4$, respectively. Given the mutation and crossover rates of 0.2 and 0.5 , an inferior local solution is found at the intersection of the two satisfactions (i.e. $O S$ and $C S$ ) where satisfaction and total unit cost are $80.3 \%$ and $\$ 372.35$, respectively. The findings confirm that it is not desirable to initialize an arbitrary pair of mutation and crossover rates for a GA experiment and that it is not appropriate to accept the solution obtained from a single run of GA as performed in existing GA studies. 
Table 2. Trade-offs corresponding to the parameters

\begin{tabular}{c|c|c|c}
\hline $\begin{array}{c}\text { Mutation } \\
\text { rate }\end{array}$ & $\begin{array}{c}\text { Crossover } \\
\text { rate }\end{array}$ & Unit cost & OS $=C S$ \\
\hline 0.2 & 0.7 & 360.04 & 0.84 \\
\hline 0.4 & 0.7 & 360.04 & 0.84 \\
\hline 0.7 & 0.8 & 360.96 & 0.84 \\
\hline 0.8 & 0.4 & 360.93 & 0.84 \\
\hline 0.6 & 0.4 & 364.47 & 0.83 \\
\hline 0.6 & 0.8 & 363.61 & 0.83 \\
\hline 0.3 & 0.6 & 365.95 & 0.82 \\
\hline 0.3 & 0.7 & 366.85 & 0.82 \\
\hline 0.2 & 0.6 & 369.63 & 0.81 \\
\hline 0.3 & 0.5 & 368.48 & 0.81 \\
\hline 0.6 & 0.2 & 368.42 & 0.81 \\
\hline 0.7 & 0.7 & 368.59 & 0.81 \\
\hline
\end{tabular}

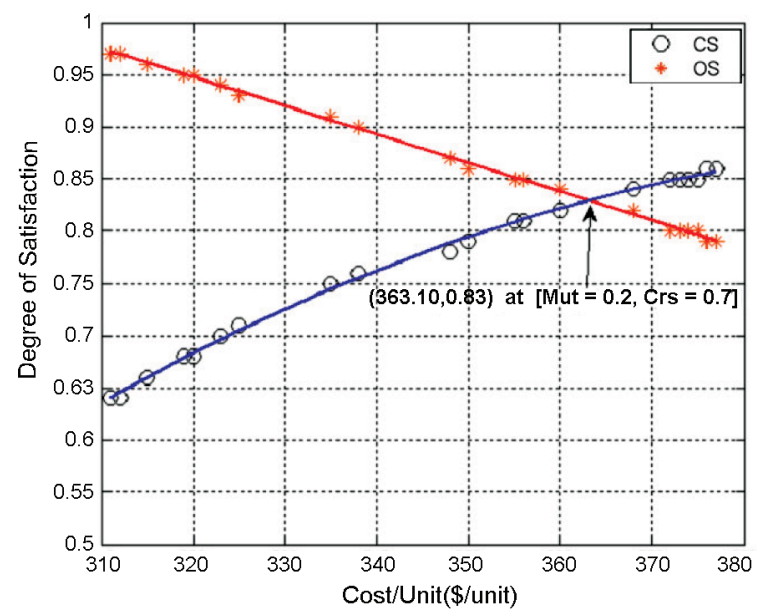

Fig. 5. Trade-off between $O S$ and $C S$

Table 3. Sample Pareto optimal solutions

\begin{tabular}{cccc}
\hline Pareto optimal solutions & OS & CS & Unit cost \\
\hline $0.35,0.67,0.42,0.71,0.60,0.27,0.51,0.81,0.41,0.75,0.76,0.40$ & 0.79 & 0.86 & 350 \\
$0.38,0.49,0.41,0.65,0.59,0.28,0.58,0.79,0.66,0.76,0.81,0.36$ & 0.81 & 0.85 & 355 \\
$0.38,0.48,0.42,0.75,0.63,0.29,0.58,0.77,0.62,0.76,0.83,0.39$ & 0.82 & 0.84 & 360 \\
$0.39,0.72,0.41,0.67,0.60,0.28,0.57,0.79,0.64,0.74,0.81,0.44$ & 0.84 & 0.82 & 368 \\
$0.33,0.72,0.48,0.74,0.61,0.29,0.56,0.80,0.75,0.75,0.77,0.40$ & 0.85 & 0.80 & 372 \\
\hline
\end{tabular}

Sensitivity analysis is inevitable for a GA experiment. However, it requires the user's frequent intervention which is cumbersome and time consuming because a pair of mutation and crossover rates should be reset iteratively by manual operation. The automation of sensitivity analysis in SQCO improves the search performance of the GA experiment by identifying the optimal set of mutation and crossover rates without the user's intervention.

To execute the GA experiment, the optimal set of mutation and crossover rates was used to initialize the options of a new GA experiment. With these options, the GA was executed for the number of simulation runs defined by the user. The reliability of the system was improved by accepting the fittest of all the simulation outputs as the global solution. SQCO implements QFD, GA, sensitivity analysis, and simulation in a single software system. The system identifies the optimal set of mutation and crossover rates by performing sensitivity analysis and computes the optimal global solution by executing the GA algorithm iteratively without the user's intervention at any time. Table 2 represents the GA output, i.e. the trade-off between owner/contractor satisfactions and the allowable budget, when the options (i.e. mutation and crossover rates) were adjusted. It is found that the optimal solution is obtained at the satisfaction trade-off of $80 \%$ and an allowable cost of $\$ 360.04$ when the mutation rate of 0.2 and the crossover rate of 0.7 are used.

The GA experiment is performed using the optimal set of options (i.e. population size: 72 ; mutation: 0.2 ; and crossover: 0.7 ) computed by sensitivity analysis. The GA outputs obtained from the GA experiment with the op- timal options are as follows: the number of Pareto front solutions is 25 , the computation time is 14.87 seconds; the number of generations is 120 , the average distance of the Pareto front is 0.068 , and the spread of the Pareto front is 0.181 .

Figure 5 illustrates owner satisfactions and contractor satisfactions in proportion to the cost of a curtainwall unit when the 25 Pareto front solutions were used as QFD input variables. The 25 Pareto optimal solutions were plotted in a two dimensional surface (i.e. satisfaction index vs. allowable budget). The trade-offs of owner and contractor satisfactions are between $82 \%$ and $84 \%$ and the corresponding allowable budgets are between $\$ 360$ and $\$ 368$. Five of the 25 Pareto optimal solutions are obtained as shown in Table 3.

\section{Conclusions}

SQCO implements a HoQ model that computes construction owner satisfaction and contractor satisfaction in a curtain-wall design by using Quality Function Deployment (QFD). The system computes the optimal set of planned achievements of the curtain-wall components yielding an optimal trade-off of owner and contractor satisfaction. It integrates MOGA to effectively solve the multi objective optimization problem and implements an automated sensitivity analysis to facilitate the identification of the optimal mutation and crossover rates in the system. A global solution is obtained from this new GA experiment. The system improves the reliability of the GA experiment by reducing the variability of the GA output normally at- 
tributed to random number generation and to arbitrary option setting. It provides the decision maker with what is the optimal set of budget allocations to the components, computes Pareto optimal solutions using the multi-objective genetic algorithm (MOGA), determines the optimal solution by which the conflicting interests of the project participants are optimally compromised, and quantifies the extent of the variance of their satisfactions in proportion to the budget allocation.

SQCO helps: (1) to expedite decision making in the design phase, because it has the capability to compute owner and contractor satisfactions simultaneously; (2) to find a trade-off that leads to the efficient allocation of the budget and the improvement of construction quality; (3) to select optimal design alternatives of construction methods and operations; and (4) to efficiently identify the optimal global solution by finding the optimal set of mutation and crossover rates using the hybridized system with QFD, GA, sensitivity analysis, and simulation, and by executing the GA algorithm iteratively without the user's intervention at any time.

As presented in the test case, one may rapidly execute the system by integrating the owner requirements and their weights of importance, the architects' expert opinions, and the cost information obtained from specialty contractors. The case study that selected an optimal design alternative for a metal curtain-wall unit verifies the validity of the system.

The system is applicable only to curtain-wall construction, since the surveys that investigate the construction owner's needs and expectations, the architects' expert opinions, and the specialty contractor's views have been conducted only for this construction method. However, the system could easily be extended to allow the user to resize the number of the owner's requirements and the number of technical attributes and to link with a database that accommodates survey data, etc. The methodology of SQCO can be reused even if new data should be collected for other construction method.

\section{Acknowledgments}

This research was supported by Basic Science Research Program through the National Research Foundation of Korea (NRF) funded by the Ministry of Science, ICT \& Future Planning (NO. 2013R1A2A2A01068316). The contribution of the Ministry of Science, ICT \& Future Planning is gratefully acknowledged.

\section{List of abbreviations}

$d_{i}$ - relative importance weights of the $i^{\text {th }}$ customer requirement;

$R_{i j}$ - degree in which the $j^{\text {th }}$ curtain-wall component (TA) contributes to satisfy the $i^{\text {th }}$ owner requirement (CR) in full;

$R^{*}{ }_{i j}$ - normalized strength of the relationship between the $j^{\text {th }}$ curtain-wall component and the $i^{\text {th }}$ owner requirement;
$T_{j k}$ - degree of correlation between the $j^{\text {th }}$ and $k^{\text {th }}$ curtain-wall component (TA);

$y_{j}-$ degree of the planned achievement of curtain-wall components;

$x_{j}-$ degrees of the actual attainment of TAs into QFD to quantify the level of customer satisfaction;

$\theta_{0}$ - satisfaction threshold;

$w_{j}-j^{\text {th }}$ normalized importance weight of curtain-wall components;

$w_{j}^{*}-j^{\text {th }}$ actual importance weight of curtain-wall components;

$c_{j}-j^{\text {th }}$ primary costs of curtain-wall components;

c - summation of the primary costs of curtain-wall components $\left(c_{j}\right)$;

$c^{*}$ - sum total of actual costs of curtain-wall components $\left(c^{*}\right)$;

$C_{j}\left(x_{j}\right)$ - planned costs calculated using the actual costs $\left(c^{*}\right)$ and the degree of actual achievement $\left(x_{j}\right)$;

$C$ - sum total of planned costs of all components which is the unit cost of a curtain-wall;

$O S$ - owner satisfaction;

$C S$ - contractor satisfaction;

$C_{0}$ - minimum planned cost;

$B$ - allowable budget;

$\alpha_{0}$ - satisfaction with total budget committed;

$r \quad$ - coefficient of curve shape.

\section{References}

Bode, J.; Fung, R. Y. K. 1998. Cost engineering with quality function deployment, Computers and Engineering 35(3-5): 587-590.

Çelik, B.; Girgin, S.; Yazici, A.; Ünlü, K. 2010. A decision support system for assessing landfill performance, Waste Management 30(1): 72-81. http://dx.doi.org/10.1016/j.wasman.2009.09.016

Cha, Y.-J.; Raich, A. M.; Barroso, L. R.; Agrawal, A. K. 2011. Optimal placement of active control devices and sensors in frame structures using multi-objective genetic algorithms, Structural Control and Health Monitoring 20(1): 16-44. http://dx.doi.org/10.1002/stc.468

Chew, M. Y. L.; Tan, S. S.; Kang, K. H. 2004. A technical evaluation for curtain-wall and cladding facades, Structural Survey 22(4): 210-227. http://dx.doi.org/10.1108/02630800410563750

Deb, K. 1999. Multi-objective genetic algorithms: problem difficulties and construction of test problems, Evolutionary Computation 7(3): 205-230. http://dx.doi.org/10.1162/evco.1999.7.3.205

Deb, K. 2001. Multi-objective optimization using evolutionary algorithms. New York: Willey. 518 p.

Du, G.; Karoumi, R. 2013. Life cycle assessment of a railway bridge: comparison of two superstructure designs, Structure and Infrastructure Engineering: Maintenance, Management, Life-Cycle Design and Performance 9(11): 11491160. http://dx.doi.org/10.1080/15732479.2012.670250

Eamon, C. D.; Jensen, E. A.; Grace, N. F.; Shi, X. 2012. LifeCycle Cost Analysis of alternative reinforcement materials for bridge superstructures considering cost and maintenance uncertainties, Journal of Materials in Civil Engineering 24(4): 373-380.

http://dx.doi.org/10.1061/(ASCE)MT.1943-5533.0000398 
Efstathiades, C.; Baniotopoulos, C. C.; Nazarko, P.; Ziemianski, L.; Stavroulakis, G. E. 2007. Application of neural networks for the structural health monitoring in curtainwall systems, Engineering Structures 29(12): 3475-3484. http://dx.doi.org/10.1016/j.engstruct.2007.08.017

El-Rayes, K.; Kandil, A. 2005. Time-Cost-Quality Trade-Off Analysis for highway construction, Journal of Construction Engineering and Management 131(4): 477-486. http://dx.doi.org/10.1061/(ASCE)0733-9364(2005)131: 4(477)

Eisele, J.; Kloft, E. 2002. High-rise manual: typology and design, construction and technology. Boston: Birkhauser. 235 p.

Fayek, A. R.; Rodriguez, F.; Jose, R. 2010. Application of fuzzy logic to quality assessment of infrastructure projects at conceptual cost estimating stage, Canadian Journal of Civil Engineering 37(8): 1137-1147. http://dx.doi.org/10.1139/L10-036

Fung, R. Y. K.; Tang, J.; Tu, Y.; Wang, D. 2002. Product design resources optimization using a non-linear fuzzy quality function deployment model, Internal Journal of Production Research 40(3): 585-599. http://dx.doi.org/10.1080/00207540110061634

Goldberg, D. E. 1989. Genetic algorithms in search, optimization, and machine learning. Reading: Addison Wesley, Massachusetts. $432 \mathrm{p}$.

Kanagaraj, G.; Mahalingam, A. 2011. Designing energy efficient commercial buildings - a systems framework, Energy and Buildings 43(9): 2329-2343. http://dx.doi.org/10.1016/j.enbuild.2011.05.023

Kracka, M.; Brauers, W. K. M.; Zavadskas, E. K. 2010. Buildings external walls and windows effective selection by applying multiple criteria method, in The $10^{\text {th }}$ International Conference "Modern Building Materials, Structures and Techniques”, 19-21 May 2010, Vilnius, Lithuania. Selected papers, Vol. 1. 436-441.

King, B. 1987. Better designs in half the time: implementing QFD in America. Methuen: Goal/QPC. 315 p.

Law, M. A.; Kelton, W. D. 2000. Simulation modeling and analysis. $3^{\text {rd }}$ ed. Boston: McGraw-Hill. 792 p.

Lee, S.-I.; Bae, J.-S.; Cho Y.-S. 2012. Efficiency analysis of setbased design with structural building information modeling (S-BIM) on high-rise building structures, Automation in Construction 23: 20-32. http://dx.doi.org/10.1016/j.autcon.2011.12.008

Oh, S.; Kim, Y.; Park, C.; Kim, I. 2011. Process-driven BIMbased optimal design using integration of energy plus, genetic algorithm, and Pareto optimality, in The $12^{\text {th }}$ Conference of International Building Performance Simulation Association, 14-16 November 2011, Sydney, Australia, 894-901.

Ojo, S. O.; Ain, O.; Adeyem, A. Y. 2011. A comparative analysis of the performance of traditional contracting and
Design-Build procurements on the client objectives in Nigeria, Journal of Civil Engineering and Management 17(2): 227-233.

http://dx.doi.org/10.3846/13923730.2011.574449

Peach, R. W. 1997. The ISO 1900 handbook. $3^{\text {rd }}$ ed. Times Mirror Higher Education Group, Inc. 800 p.

Raharjo, H.; Xie, M.; Brombacher, A. C. 2006. Prioritizing quality characteristics in dynamic quality function deployment, International Journal of Production Research 44(23): 5005-5018. http://dx.doi.org/10.1080/00207540600547414

Suh, W.-J.; Park, C.-S.; Kim, D.-W. 2011. Heuristic vs. Metaheuristic optimization for energy performance of a post office building, in The $12^{\text {th }}$ Conference of International Building Performance Simulation Association, 14-16 November 2011, Sydney, Australia, 704-711.

Tang, J.; Fung, R. Y. K.; Xu, B.; Wang, D. 2002. A new approach to quality function deployment planning with financial consideration, Computers \& Operations Research 29(11): 1447-1463. http://dx.doi.org/10.1016/S0305-0548(01)00041-7

Tchidi, M. F.; He, Z.; Li, Y. B. 2012. Process and quality improvement using Six Sigma in construction industry, Journal of Civil Engineering and Management 18(2): 158-172. http://dx.doi.org/10.3846/13923730.2012.657411

Tsai, Y.-T.; Chang, Y.-M. 2004. Function-based cost estimation integrating quality function deployment to support system design, The International Journal of Advanced Manufacturing Technology 23(7): 514-522. http://dx.doi.org/10.1007/s00170-003-1564-7

Wasserman, G. S. 1993. On how to prioritize design requirements during the QFD planning process, IIE Transactions 25(3): 59-65. http://dx.doi.org/10.1080/07408179308964291

Wang, N. 2011. Multi-criteria decision-making model for whole life costing design, Structure and Infrastructure Engineering 7(6): 441-452. http://dx.doi.org/10.1080/15732470802670875

Wang, N.; Chang, Y.-C.; Nunn, C. 2010. Lifecycle assessment for sustainable design options of a commercial building in Shanghai, Building and Environment 45(6): 1415-1421. http://dx.doi.org/10.1016/j.buildenv.2009.12.004

WBDG. 1993. Building envelope design guide-curtain walls [online], [cited 12 October 2012]. Available from Internet: http://www.wbdg.org/design/env_fenestration_cw.php

Zitzler, E.; Laumanns, M.; Thiele, L. 2001. SPEA2: Improving the Strength Pareto Evolutionary Algorithm. Technical Report 103. Computer Engineering and Communication Networks Lab (TIK). Swiss Federal Institute of Technology (ETH) Zurich, Gloriastrasse 35, CH-8092 Zurich.

Tae-Kyung LIM. PhD, is a research fellow in the School of Architecture and Civil Engineering at Kyungpook National University. $\mathrm{He}$ is currently working on a research project whose objective is to develop construction quality-cost optimization system using stochastic simulation techniques.

Won-Suk JANG. PhD is an Assistant Professor in the Department of Civil Engineering, College of Engineering at Yeungnam University, South Korea. Member of Korean Society of Civil Engineers (KSCE), Korea Institute of Construction Engineering and Management (KICEM), Korean Society of Ubiquitous Monitoring (KSUM), and Korean Institute of Building Information Modeling (KIBIM). His research interests include IT-based Civil and Infrastructure Engineering and Management, such as applications of wireless sensor network, IT-based maintenance systems, and construction assets tracking. 
Jae-ho CHOI. PhD is an Assistant Professor in the Department of Civil Engineering, College of Engineering at Dong-A University, South Korea. Member of Korean Society of Civil Engineers (KSCE) and Korea Institute of Construction Engineering \& Management (KICEM). His research interests are divided into two broad categories: (1) Quality management process improvement using 3D Engineering technology in the domain of civil infrastructure and plant facility, and (2) Analysis of Integrated Business (IB) model and its variations in Public-Private Partnership (PPP) infrastructure projects.

Dong-Eun LEE. PhD, ISO 9000 QMS Auditor, had worked for School of Engineering at Southern Illinois University Edwardsville (SIUE) in USA as an Assistant Professor. He is a tenured Professor in the School of Architecture and Civil Engineering at Kyungpook National University, South Korea. Member of American Society of Civil Engineers (ASCE), Korean Society of Civil Engineers (KSCE), Korea Institute of Construction Engineering and Management (KICEM), and Architectural Institute of Korea, etc. His research interests include: (1) Construction business process modeling and automation; (2) Workflow Management Systems (WfMS) in construction; (3) Simulation based scheduling method; (4) Stochastic simulation and Quantitative analysis; (5) Construction quality and safety. Dr. Lee's major research effort has been focusing on developing and employing simulation techniques for resolving issues in construction. His research interest also includes Expert system and general computer applications in construction. 